\title{
The Research Advances of Bioremediation Technology on the Petroleum Pollution Treatment
}

\author{
Qiuhua Shen ${ }^{1, a}$, Xiaojie Wang ${ }^{1, b}$, Zhenchao Ma ${ }^{2}$ Shuang Wang ${ }^{1, \mathrm{c}}$ \\ ${ }^{1} 1$ Naval Logistical College, Tianjin 300450, PR China \\ ${ }^{2}$ Energy Development Co., Ltd. CNOOC, Tianjin 300450, PR China
}

\begin{abstract}
Petroleum pollution has become a well concerned environmental problem. Renovating and controlling the petroleum pollution is an important guarantee to recover the environmental function. In recent years, the effect of bioremediation technology in eliminating petroleum pollution has been concerned by people gradually, of which, the effect of microorganism is the most important part. The paper discusses the source of petroleum pollution, the hazard of petroleum pollution, bioremediation mechanism and bioremediation technology of petroleum pollution and prospects the development trend and application of microorganism in renovating water in the petroleum pollution.
\end{abstract}

\section{Introduction}

After the petroleum enters water, it is difficultly degradable in a short time, and petroleum hydrocarbon compound increases the carbon content in the water and endangers the ecological system of water ${ }^{[1]}$. Toxic aromatic hydrocarbon compound pollutes water, enters food chain through animals and plants such as fish, and endangers the life and survival of people. In recent years, the petroleum pollution of water has become generally concerned problem across the world, and the effective renovation and comprehensive treatment of the polluted water have become people's research focus.

The renovation method of petroleum polluted water includes physical method, chemical method and biological method according to the principle ${ }^{[2]}$. At present, it is very common to use physical and chemical methods. Physical method utilizes oil containment booms, oil slicks recovery ship, oil skimmers, portable oil reservoirs, oil trawls, and other equipment to block the oil in the water, block the contaminated area, and then use mechanical equipment collecting petroleum hydrocarbons for recycling. Although the physical methods are simple and have little secondary pollution to the environment, they are costly. The physical methods mainly deal with large-scale, huge oil spill accidents on the sea surface, and it is not very effective for dealing with the petroleum hydrocarbons with relatively low density, low viscosity, and fast diffusion speed. Chemical methods mainly use chemical agents such as dispersants and detergents to disperse slicks into small oil droplets, to dissolve or settle into water bodies. Although the chemical method can maximally treat petroleum-based compounds, it also easily generates a large amount of particulate matter and gases such as carbon dioxide and sulfur dioxide. Additionally, chemical reagents used in this method can cause secondary pollution to the environment.

Bioremediation refers to a controlled or spontaneous biological catalysis and degradation process of environmental pollutant so as to reduce or finally eliminate the environmental pollution. Compared with traditional physical and chemical methods, the bioremediation method could eliminate marine petroleum pollution effectively, and causes less impact on people and environment. The renovation cost is low and it is free of secondary pollution ${ }^{[1-3]}$. The bioremediation is the most important way to eliminate petroleum pollution completely. The bioremediation technology that uses microorganisms for degradation to actively remove petroleum hydrocarbon compounds has received increasing attention. It can not only enhance the ability of the environment to repair itself, but also provide bacterial resources for bioremediation. Bioremediation technology has become a core technology of controlling petroleum pollution.

\section{Source of petroleum pollution}

Oil pollution in water mainly comes from the discharge of industrial, agricultural, transportation and domestic sewage, and oil leakage, the settlement of petroleum hydrocarbon compounds that escape into the atmosphere, and natural oil spills on the sea floor. There are many kinds of industrial wastewater that contains oil pollutants, which mainly include refinery sewage, petroleum exploration and development wastewater, ballast water and so on.

According to input type, petroleum pollution can be divided into sudden input and chronic input. The sudden input includes cruise accident, offshore petroleum exploration leakage, and petroleum exploitation blowout 
accident. Chronic input includes petroleum sewage discharged by the ship, oil-field wastewater emitted at sea, natural seabed leakage, industrial wastewater discharge, oily exhaust gas sedimentation, etc. In addition, the marine transportation and handling process of petroleum may cause oil spill accident.

\section{Hazard of petroleum pollution}

The major hazard of petroleum pollution is impact on marine environment and marine ecosystem. The marine ecosystem has sensitive or fragile link to petroleum hydrocarbon compound substance and the damaged ecosystem needs several years or dozen year to recover. The hazard of petroleum pollution is mainly reflected in the following aspects.

In the first place, after petroleum enters the sea, it makes a layer of petroleum film covered on the surface. The petroleum film obstructs the exchange of $\mathrm{O}_{2}, \mathrm{CO}_{2}$, etc, affects the photosynthesis of marine phytoplankton, and causes the death of algae and phytoplankton; the degradation of petroleum pollutant consumes the dissolving oxen in the water, damages the oxygen balance of sea and results in anoxia of seawater and thus results in death of creative; the petroleum film could stick a lot of roes and juvenile fish, triggers death of roes and distortion of juvenile fish, make the fish and shrimp emit petroleum odor and lose the edible value ${ }^{[4]}$.

In in the next place, water solubility in the petroleum has direct toxic action on the fish. It makes the fish be toxic or dead. The fish and shellfish, once eaten by the people, it causes serious harm to human body because some hazardous substances are accumulated in them since they lived in the polluted seawater in a long time ${ }^{[5]}$.

At last petroleum pollutant easily approximates to the shore and tarnishes the attractive coast recreation place such as beach, affects the image of coastal city and thus affects the development of costal tourism.

\section{Bioremediation mechanism}

Bioremediation refers to a controlled or spontaneous biological catalysis and degradation process of environmental pollutant so as to reduce or finally eliminate the environmental pollution. In the bioremediation process, inoculating specific petroleum degrading bacteria, adding nutrient or surfactant, providing electron acceptor and co-metabolism substrate as well as optimal treatment condition can enhance the spontaneous degradation process of petroleum pollutant by the indigenous microorganism in the environment and finally transforms the petroleum pollutant to non-toxic end product.

Petroleum is a complicated compound composed of thousands of compounds with different natures. hydrocarbon compound substance is the most constituent, the remaining is non-hydrocarbon compound organic matter containing nitrogen, sulfur and oxygen, etc ${ }^{[6]}$. Petroleum hydrocarbon compound is a natural organic matter, so microorganism can use petroleum as carbon source. The degrading enzyme of microorganism has oxidation reduction, decarboxylation, deamination, dehydration, hydrolysis and various other chemical effects. Thus, various hydrocarbon compound substances contained in petroleum can be degraded by the metabolism of microorganism. Microorganism has such advantages as wide variety, wide distribution, small volume, fast breeding, large specific surface area and easy variation, also shows efficiency and diversity in the environmental control.

\section{Bioremediation technology of petroleum pollution}

Bioremediation technology based on biodegradation is mainly to enhance the petroleum degradation rate, and transform the petroleum pollutant to non-toxic metabolite. Bioremediation of petroleum pollution mainly includes three methods.

\subsection{Add surfactant}

Adding surfactant increases the contact area between petroleum and microorganism in the water and promotes microorganism to use petroleum. The solubility of petroleum in the water is very low, which restricts microorganism from taking in and using the carbon source and oxygen. Surface active matter emulsifies the petroleum pollutant in the liquid phase, increases the contact surface area between microorganism and oil drop, and makes for direct contact of microorganism cell and oil drop. Surfactant can also change the surface characteristic of bacterial cell, makes the surface of bacterial cell become more lyophobic, increases the affinity of cell and petroleum pollutant and promotes microorganism to degrade petroleum substance. Saeki et al have studied that biosurfactant produces bacterial JE1058 and produces biodegradation effect. The result indicates that JE1058 can promote the dissolution of oil and enhances the biodegradation of oil obviously [7]. Using bacteria Pseudomonas saccharophila 1 and Pseudomonas saccharophila 2, Churchill et al have studied the effect of three nonionic surfactants on the petroleum biodegradation rate. The result shows that three surfactants promotes oil to disperse in the aqueous solution, and enhances biodegradation rate of oil obviously. However, when Churchill uses bacteria P.putida, three surfactants inhibits the biodegradation of petroleum. Thus, they think that the different effect of surfactant in two researches may be owing to the difference of surface structure of the used bacterial cell ${ }^{[8]}$. In addition, surfactant may be toxic and the toxicity may be accumulated in the environment and triggers corresponding ecological problem and social problem. Many surfactants causes environmental pollution owing to the toxicity. Thus, in the practice, the surfactant manufactured with microorganism is usually used to accelerate the degradation of petroleum. 


\subsection{Add bacterial strain with efficient degradability so as to increase the population quantity of microorganism}

According to the existing research, more than 200 kinds of microorganism can degrade petroleum. In normal situation, the microorganism under mixed culture has higher degradation efficiency than that under pure culture. For example, Wang Zhiqiang et al screen three kinds of bacterial strains that could degrade petroleum efficiently from the petroleum polluted soil. They are identified as pseudomonas, flavobacteirum and micrococcus. The petroleum degradation rate of these three bacteria strains is $62 \%, 56 \%$ and $52 \%$. Moreover, they verify that the mixed use effect of these three bacteria strains is superior to the separate use effect, and the petroleum degradation rate of compound bacteria reaches $85 \%{ }^{[9]}$.

After biological modification, the superbacteria can remove petroleum pollutant efficiently. Thus, it is deemed as a renovation technology with development prospect. Zheng Jinxiu et al separate two strains of efficient petroleum degrading bacteria $\mathrm{W} 1$ and $\mathrm{W} 2$ from the soil nearby petrochemical plant, which are acinetobacter and bacillus bacteria. They exert UV mutagenesis and obtain mutation bacterium ${ }^{[10]}$. They carry out transformation ratio experiment against the bacteria strain before and after mutation. The experimental result indicates that when the bacteria strain before mutation is cultured for $10 \mathrm{~d}$ in the culture solution with the petroleum concentration $4000 \mathrm{mg} / \mathrm{L}$, the petroleum degradation rates are $74.34 \%$ and $77.58 \%$ respectively. On the same condition, the petroleum degradation rates of the bacteria strain after mutation reach $79.9 \%$ and $87.3 \%$. In addition, the result also indicates that with the increasing of petroleum concentration, the efficiency of mutation bacteria is more obvious, and the endurance capacity of mutation bacteria to high-concentration petroleum was enhanced greatly.

Petroleum pollutant contains various hydrocarbon compound compounds, but petroleum degrading bacteria can only degrade one petroleum component, and petroleum degrading bacteria in the natural environment cannot degrade various petroleum components efficiently. The petroleum degradation needs the participation of more bacteria strains, but competition may exist among different bacteria strains and exerts negative effect on the degradation. Thus, it was a necessity to use gene engineering bacteria to remove petroleum pollutant ${ }^{[11]}$. Gene engineering bacteria is recombining the degrading genes of different bacteria and combining the metabolism approaches of pollutant in different bacteria to form super degrading bacteria with special degradation function and enhance the degradability of bacteria and enhance the bioremediation effect.Researchers find that Pseudomonas. aeruginosa, as the acceptor, shifts various plasmids carried by pseudomonas putida and formed gene engineering bacteria. The petroleum pollutant removing capacity of such gene engineering bacteria is over ten thousand times than that of natural bacteria. General Electric Company constructs superbacteria containing four plasmids through recombining DNA technology, and the petroleum hydrocarbon compound degradability is dozen and hundred times than that of wild fungus. It takes over one year for wild fungus to degrade the same area of marine oil, but superbacteria only takes several hours.

\subsection{Add nutritive salt such as $N$ and $P$ to promote the metabolism of microorganism}

Utilizing the gene engineering technique can shorten petroleum renovation period, but new species or new gene information brings about the risk of ecological invasion, so gene engineering bacteria is still a controversial problem. More people study petroleum degradation through adding nutritive salt. Petroleum can provide organic carbon easily used by the creature, but fails to provide nutrient substance such as $\mathrm{N}$ and P. In the petroleum polluted water, usually the content of organic carbon is high, but $\mathrm{N}$ and $\mathrm{P}$ are relatively insufficient. Thus, adding appropriate amount of $\mathrm{N}$ and $\mathrm{P}$ nutrient can promote biodegradation. At present, nutritive salt mainly includes three types, such as waters solubility type, sustained-release type, and lipophilic type. Sustained-release type has proper release rate. It supplements nutrition for the growth and breeding of petroleum degrading bacteria continuously, so it is ideal nutrition source. Lipophilic fertilizer can make the nutritive salt dissolving in the oil and nutritive salt in the oil phase can promote the growth of bacteria. In the experiment, He Yunxin et al adopt petroleum degrading bacteria at oil spill site and add sustained-release fertilizer at the same time ${ }^{[12]}$. Result indicates that in the bioremediation process, the sustained release fertilizer speeds up the growth and breeding of petroleum degrading bacteria, forms dominant bacterial community at pollution site and thus reaches good bioremediation effect.

\section{Factors Affecting Bioremediation of Petroleum Pollution}

\section{1 physical properties of petroleum}

The physical state of oil in water has a great influence on the biodegradation of petroleum. Liquid hydrocarbons can be ingested by bacteria and then infiltrate into the cell membrane. Petroleum hydrocarbon compounds that are in a water-soluble state in the environment are more likely to be degraded. If it is a solid petroleum hydrocarbon compound, microorganisms for degradation can hardly be used directly. In petroleum hydrocarbon compounds that are not dissolved in water, only compound at the interface between the oil and water can contact with microbial cells. With the influence of surface tension on different surfaces, the probability of being degradable is much smaller ${ }^{[7]}$. When petroleum is present in water as an oil-in-water emulsion, the volume of the oil is small and dispersed, thus the surface area of the oil is increased as well as the contact area of the 
microorganism. However, a large number of massive and flaky oil-in-water can cause the oil to be relatively concentrated, that is, the surface area of oil under the same volume is reduced, and biodegradation is declined.

The different petrochemical components also affect the rate at which they are degraded. In general, saturated hydrocarbons are most easily degraded by microorganisms, followed by low molecular weight aromatic hydrocarbon compounds. High molecular weight aromatic hydrocarbons and resins are difficult to degrade. The degradation rate patterns of different hydrocarbon compounds are: normal alkanes $>$ branched alkanes $>$ low molecular weight aromatic hydrocarbons $>$ high molecular weight aromatic hydrocarbons. When the oil concentration is low, it can be dissolved in water, but the vast majority of oil spill incidents release petroleum hydrocarbon compounds far beyond the range that can be dissolved. High concentrations of oil often produce thick oil layers that are difficult to disperse, resulting in water that lacks of nutrients and oxygen therefore inhibits the biodegradation of petroleum. With the increase of petroleum concentration, the final degradation rate of oil by microorganisms gradually decreases.

\section{2 environment factors}

Temperature can significantly affect the oil degradation rate. Temperature affects the biodegradation efficiency of petroleum in two ways. On the one hand, temperature directly affects the growth, reproduction, and metabolism of bacteria; on the other hand, temperature can affect the physical and chemical properties of oil in the ocean. A microorganism can only grow within a certain temperature range, where the most suitable growth temperature exists. When the temperature drops, the degree of viscosity of the oil increases, the volatilization of the short-chain alkane weakens, the solubility of the water increases, the activity of the enzyme decreases, and the efficiency of degradation of the oil by the microorganism decreases. Therefore, choosing the right temperature is critical for the growth and reproduction of the microorganisms and for the degradation rate of petroleum.

Microbial degradation of petroleum usually occurs under aerobic conditions, and biodegradation is at low rates under anaerobic conditions. Although some scholars have demonstrated that microorganisms can also degrade petroleum hydrocarbons under anaerobic conditions. However, the biodegradation of petroleum under anaerobic conditions is much slower than that under aerobic conditions in most cases.

$\mathrm{pH}$ affects the degradation activities of microorganisms, because microorganisms need to survive in a certain range of $\mathrm{pH}$. $\mathrm{pH}$ changes will cause changes in microbial activity. High or low $\mathrm{pH}$ are not suitable for microbial degradation of petroleum. The microbial degradation of most petroleum hydrocarbon compounds is generally at a neutral $\mathrm{pH}$, and fungi can adapt to a certain acidic environment. The extreme $\mathrm{pH}$ environment is detrimental to the growth of microorganisms. However, there are also microorganisms that can degrade petroleum hydrocarbons under extreme $\mathrm{pH}$ conditions. Under other environmental conditions, such as $\mathrm{Fe}^{2+}$ concentration, salinity, and pressure can also affect microbial degradation of petroleum hydrocarbons. In general, with the increase of salt concentration in the environment, the degradation rate of petroleum hydrocarbon compounds decreases, that is, the degradation of petroleum contaminants in freshwater will degrade faster than the petroleum contaminants in the ocean ${ }^{[7]}$.

\section{3 biological factors}

The type and quantity of microorganisms have a significant effect on the degradation of petroleum. Microorganisms in the environment generally have the ability to utilize petroleum for metabolism, and the ability of different microbial species to degrade oil is quite different. The same strain also has great differences in the ability for using petroleum hydrocarbon compounds. In general, oil degradation rate from mixed cultured microorganisms is faster than single strain culture. Before choosing the microbial community that degrades petroleum hydrocarbon compounds, it is important to examine whether petroleum hydrocarbon compounds can be biodegraded in a relatively fast manner.

\section{Conclusions}

At present, bioremediation technology of petroleum pollution has great development potential and it is deemed as most economic and efficient renovation method. Microorganism degradation of petroleum hydrocarbon compound pollutant is a complicated process. The degradation effect depends on the composition of surroundings and microflora. The type of microorganism, the nature of petroleum pollutant and environmental factor affect the microorganism to degrade the petroleum. Environmental factor imposes certain limitation to the bioremediation technology. Thus, it is necessary to investigate the pollution site and analyze the degradation when implementing bioremediation.

\section{References}

1. C.B. Hao, G.C. Wang, J.N. Dong: Environ. Sci. 30,8 (2009)

2. R. M. Atlas : Internat Biodeter Biodegr.35, 317(1995)

3. R.A. Khan: Bull Environ Contam Toxicol.50, 6(1993)

4. G.C. Ni, Q.Z. Gao, W.F. Zhao: Production and the Environment. 5 , 2(2005)

5. H.Q. Wu, J.X.Hu , K. Fang: China. Water. Transport. 11, 2 (2011) 
6. J.G. Leahy, R.R. Colwell: Microbiological reviews. 54, 10 (1990)

7. H.Saeki, M.Sasaki, K. Komatsu: Bioresource Technology. 10, 5 (2009)

8. K. Das, A. K. Mukherjee: Bioresource Technology 98, 4 (2007)

9. Z.Q. Wang, Q. Wu: Environmntal Sci. 26, 3 (2005)

10. J.X. Zheng, Q. Peng: Environmental Science and Technology J.30, 6(2007)

11. C.S. Suzana, M.M. Claudia, M.C. Larissa: African Biotech. J.28, 6(2013)

12. Y. X. He, X.Y. Shi and S. M. Yang: Environmental Science Technology 34, 41 (2011) 